\title{
Treatment policy of surgery in small cell carcinoma of the lung: retrospective analysis of a series of 874 consecutive patients
}

\author{
KELL ØSTERLIND, MOGENS HANSEN, HEINE HØI HANSEN, PER DOMBERNOWSKY, \\ MIKAEL RØRTH
}

From the Department of Chemotherapy, RII, Finsen Institute, and the Department of Medicine C, Bispebjerg Hospital, Copenhagen

\begin{abstract}
A therapeutic policy of surgery in the treatment of small cell carcinoma of the lung was evaluated in a retrospective series of 874 consecutive patients. All patients were included in one of six clinical trials of intensive combination chemotherapy and radiotherapy, carried out during 1973-81. General criteria of resectability, including normal appearances at mediastinoscopy, were fulfilled in 33 electively operated patients and in 46 non-operated patients. An elective operation was defined as a thoracotomy performed with the intention of pulmonary resection in a patient known to have small cell carcinoma. Pneumonectomy or lobectomy was performed in $73 \%$ of the electively operated patients. Residual macroscopic or microscopic tumour tissue was left after half of these resections. Both operated patients and non-operated patients with operable tumours survived significantly longer than 696 patients deemed to have been inoperable. There was no significant difference, however, in the duration of survival between the two subsets of operable patients. According to this analysis, a treatment policy of surgery for resectable small cell carcinoma does not lead to better overall results than treatment with chemotherapy and radiotherapy alone.
\end{abstract}

Small cell carcinoma of the lung is characterised by early dissemination. Stage III disease according to the TNM classification ${ }^{1}$ is observed in over $85 \%$ of patients at the time of diagnosis ${ }^{2}$ and less than $10 \%$ of all patients have resectable tumours. ${ }^{3-5}$ The prognosis is poor, even in those with resectable tumours. $^{36-8}$ The introduction of combination chemotherapy a decade ago led to substantially improved treatment results and to diminishing indications for surgery; but progress now seems to have stopped.' Recent results from controlled trials of chemotherapy as an adjuvant to surgery ${ }^{10} 11$ have shown the superiority of the combined treatment over surgery alone. These findings have stimulated interest in the role of surgery followed by chemotherapy ${ }^{12}$ and surgery as an adjuvant to chemotherapy. ${ }^{1314}$ This trend has prompted us to

Address for reprint requests: Dr Kell $\emptyset$ sterlind, Department of Oncology II, RII, Finsen Institute, DK-2100 Copenhagen $\emptyset$, Denmark.

Accepted 15 November 1984 review a series of 874 consecutive patients with small cell carcinoma, included in trials of combination chemotherapy or irradiation or both, to compare the overall therapeutic results observed in two groups of operable patients: those receiving surgery and those not receiving surgery before chemotherapy with or without radiotherapy.

\section{Patients and methods}

From March 1973 to September 1981 six clinical trials were conducted jointly in two departments of medical oncology at the Finsen Institute and Bispebjerg Hospital, Copenhagen, investigating combination chemotherapy and irradiation in the treatment of small cell carcinoma of the lung. These studies included 874 patients aged less than 71 years. The diagnosis of small cell carcinoma, based on the World Health Organisation classification, ${ }^{15}$ was confirmed histologically in all 874 patients. All diagnostic specimens were reviewed by the pulmonary pathologists at the two participating hospitals. 
All patients were previously untreated except for some who had undergone a prior surgical resection.

Eighty seven per cent of the 874 patients were referred from four departments of pulmonary medicine or from three departmens of thoracic surgery. The remaining $13 \%$ of the patients came from departments of internal medicine. The therapeutic policy with respect to surgical resection of the primary tumour in established cases of small cell carcinoma varied among the referring departments. Thus operable patients did not necessarily undergo surgery.

Bronchoscopy, mediastinoscopy, and lung function tests were performed in most patients presenting without overt signs of metastatic dissemination. After referral to the department of medical oncology all patients underwent further staging, including bone marrow examination and peritoneoscopy with liver biopsy. Chemotherapy was instituted five to seven days after referral, two to three weeks after a possible thoracotomy. Patients dying during surgery or during the first few days afterwards are not considered in this study as they were not referred to our departments. Such patients usually constitute about $10 \%$ of all operated patients. ${ }^{3}$

The chemotherapy regimens consisted of three, four, or six of the following agents: lomustine (CCNU), cyclophosphamide, methotrexate, vincristine, doxorubicin, and etoposide. Radiotherapy was used in two of the six trials. ${ }^{16-21}$ Treatment was scheduled to be given for 18 months, when it was discontinued if restaging, including bronchoscopy and the other procedures mentioned above, showed no evidence of disease.

Candidates for the retrospective evaluation of a surgical treatment policy were all operable patients with a diagnosis of small cell carcinoma at the time surgery was decided at the department of thoracic surgery. Patients were considered operable if there were no clinical indications of distant metastases, no signs of irresectability at bronchoscopy and mediastinoscopy and provided lung function permitted pulmonary resection. Results of staging procedures performed at the departments of medical oncology thus had no influence on this definition of operability. Patients without a preoperative diagnosis of small cell carcinoma-that is, those undergoing diagnostic thoracotomy were excluded. Survival data for operable patients undergoing elective surgery were then compared with the survival results for operable but non-operated patients. With this design we intended so far as possible to mimic a prospective controlled trial.

Wilcoxon's test or the t-test was applied for comparison between quantitative variables, the option depending on the distribution of the values. ${ }^{22}$ The $\chi^{2}$ test was applied for contingency tables. Duration of survival was calculated from the first day of chemotherapy to death or to the most recent follow up. Life table and log rank analysis were used for evaluation of survival data. ${ }^{23}$

\section{Results}

One hundred and fourteen of the 874 patients (13\%) underwent thoracotomy. In 68 of these patients thoracotomy was carried out for purely diagnostic purposes. Thus elective thoracotomy with the intention of pulmonary resection was performed in 46 patients. Sixty four non-operated patients were potentially operable (table 1 and 2). Mediastinoscopy was not performed in 13 of the electively operated patients and in 18 of the potentially operable patients and these patients did not therefore fulfil the criteria for operability. These exclusions left 33 operated patients and 46 non-operated

Table 1 Operability of 760 non-operated patients with small cell carcinoma (inoperable patients excluded according to a stepwise evaluation)

\begin{tabular}{|c|c|c|c|c|}
\hline \multirow{2}{*}{$\begin{array}{l}\text { Criteria of } \\
\text { inoperability }\end{array}$} & \multicolumn{4}{|c|}{ Number of patients } \\
\hline & Inoperable & $\begin{array}{l}\text { Potentially } \\
\text { operable }\end{array}$ & Operable & Residual \\
\hline \multicolumn{5}{|l|}{ Mediastinoscopy } \\
\hline $\begin{array}{l}\text { Positive biopsy } \\
\text { Negative biopsy } \\
\text { No mediastinoscopy }\end{array}$ & $\begin{array}{l}256 \\
25^{*}\end{array}$ & & 46 & $\begin{array}{l}504 \\
433\end{array}$ \\
\hline $\begin{array}{l}\text { Mestastases to lymph nodes, skin or pleura } \\
\text { Overt disease of brain, liver or bone } \\
\text { Mediastinal metastases on chest radiograph } \\
\text { Bronchoscopic signs of unresectability } \\
\text { No prohibitive dissemination }\end{array}$ & $\begin{array}{r}240 \\
58 \\
61 \\
79 \\
13 \dagger\end{array}$ & 18 & & $\begin{array}{r}229 \\
171 \\
110 \\
31 \\
0\end{array}$ \\
\hline
\end{tabular}

*Inoperable for reasons summarised in table 2 .

†Inoperable owing to inadequate lung function. 
Table 2 Main reasons for rejecting surgery in 25 patients with small cell carcinoma and negative mediastinal node biopsies

\begin{tabular}{ll}
\hline Sign or symptom* & No of patients \\
\hline Poor general condition & 2 \\
Proximity to carina & 4 \\
Recurrent nerve paralysis & 1 \\
Brachial plexus disease & 2 \\
Pleural disease & 5 \\
Lymph node or cutaneous lesion & 8 \\
Bone metastases & 3
\end{tabular}

*Established at referring department (that is, results of subsequent staging are not included).

Table 3 Prognostic factors in 33 operable patients who had surgery and in 46 operable patients with small cell carcinoma who did not have surgery

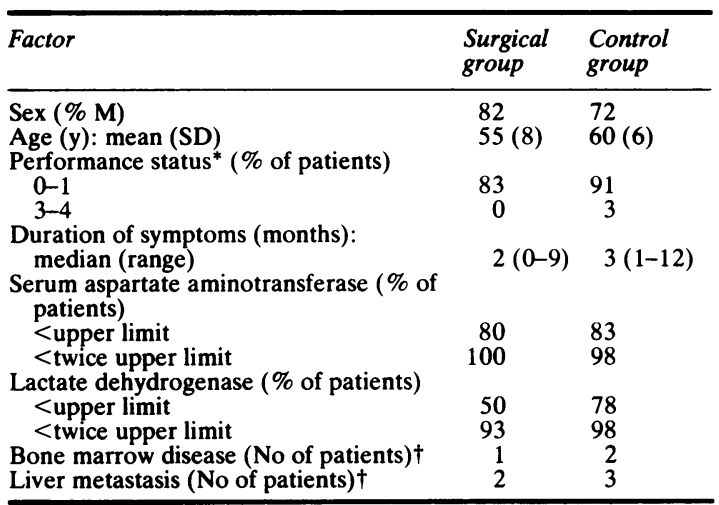

${ }^{*}$ Performance status $\left(\mathrm{AJC}^{1}\right.$ scale) at time of initiation of chemotherapy.

tObserved at routine staging before chemotherapy.

patients for analysis. The degree of selection represented by these 79 patients is illustrated by the fact that they survived significantly longer than the 696 inoperable patients $(p<0.0005)$ (fig 1$)$.

Prognostic factors of the 33 operated patients and of the 46 non-operated patients are summarised in table 3. No significant differences are observed. Distant metastases were demonstrated in about $10 \%$ of the patients in both groups as a result of staging procedures subsequently performed in the departments of medical oncology (table 3).

Table 4 summarises the treatment given to the 33 operated and the 46 non-operated patients. Resection (pneumonectomy or lobectomy) was performed in $24(73 \%)$ of the operated patients. In 11 patients (33\%) the resection was complete-that is, without macroscopic evidence of residual disease and without microscopic signs of tumour invasion of the resection margins or any structure or lymph node
Table 4 Use of chemotherapy and radiotherapy in the treatment of 33 operable patients with small cell carcinoma who underwent surgery and 46 operable but non-operated patients

\begin{tabular}{lcc}
\hline Treatment & $\begin{array}{l}\text { Surgical } \\
\text { group }\end{array}$ & $\begin{array}{l}\text { Control } \\
\text { group }\end{array}$ \\
\hline C3 & 3 & 1 \\
C3 + RL & 3 & 6 \\
C3 + RE & 4 & 3 \\
C4 & 12 & 10 \\
C4 + RL & 4 & 6 \\
C4V & 3 & 1 \\
C6 & 4 & 19 \\
\hline
\end{tabular}

RL-Irradiation of primary tumour plus mediastinum ${ }^{17} 18$. RE-RL plus brain and adrenals 17 ; C3-lomustine, cyclophosphamide, methotrexate ${ }^{1617} ; \mathrm{C} 4-\mathrm{C} 3$ plus vincristine ${ }^{18-20}$; $\mathrm{C} 4 \mathrm{~V}-$ lomustine cyclophosphamide, vincristine, etoposide ${ }^{20} ; \mathrm{C} 6-\mathrm{C} 4$ plus doxorubicin plus etoposide..$^{1421}$

outside the affected lung. Figure 2 shows the life tables of the 33 operated patients and the 46 nonoperated patients. There is no significant difference between the curves $(p=0.35)$.

Five patients in the surgical group (15\%) were disease free at restaging after 18 months of chemotherapy and seven patients in the non-surgical group (15\%). Two years' disease free survival was achieved by four and six patients respectively in the two groups. Three operated patients and two nonoperated patients are alive and free of disease after intervals ranging from more than three to more than nine years from initiation of chemotherapy. These figures do not allow meaningful statistical analysis.

Nine operated patients did not have a resection. Moving these patients to the group of non-operated patients, to focus on the effect of resection rather than the outcome of a policy of surgery, did not result in major changes of the survival curves (fig 3 ) $(\mathrm{p}=0.99)$.

Recurrent disease was proved in 24 of the operated patients and in 40 of the non-operated patients. Recurrence at the site of the primary tumour was the first clinical sign of relapse in two of 11 patients who had pneumonectomies, in one of the four who had lobectomies, in all nine who were operated but did not have a resection, and in 32 of the 40. At postmortem examinations, however, residual or recurrent small cell carcinoma at the primary site or in the mediastinal lymph nodes were proved in $9 / 10,3 / 4,6 / 6$, and $23 / 25$ respectively of patients undergoing a necropsy.

\section{Discussion}

The role of surgery in the treatment of small cell carcinoma is a controversial issue. ${ }^{24-26}$ Any assessment of its value is necessarily based on retrospec- 


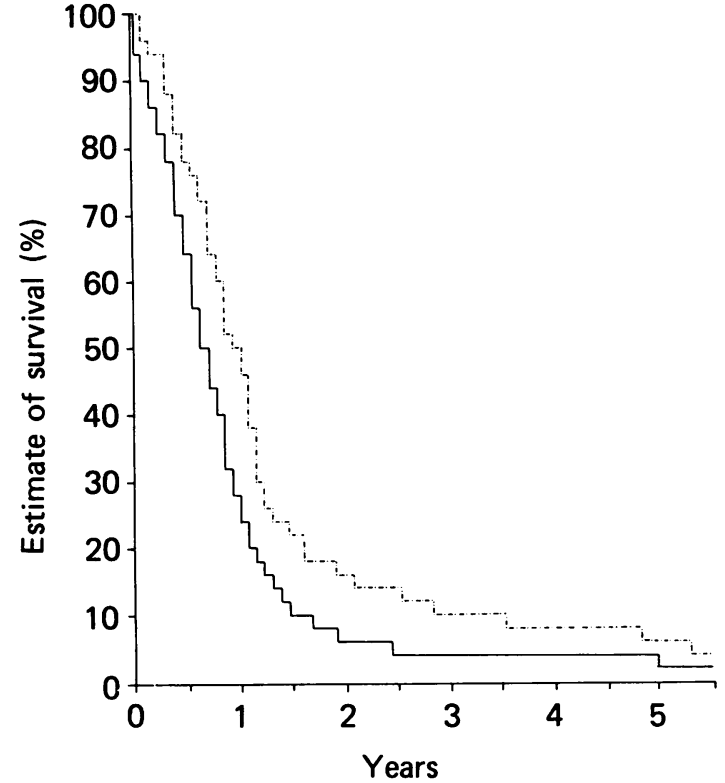

Fig 1 Life table for 33 operated patients and 46 operable but non-operated, patients (-.-.-) compared with the survival curve for 696 inoperable patients with small cell carcinoma (-).

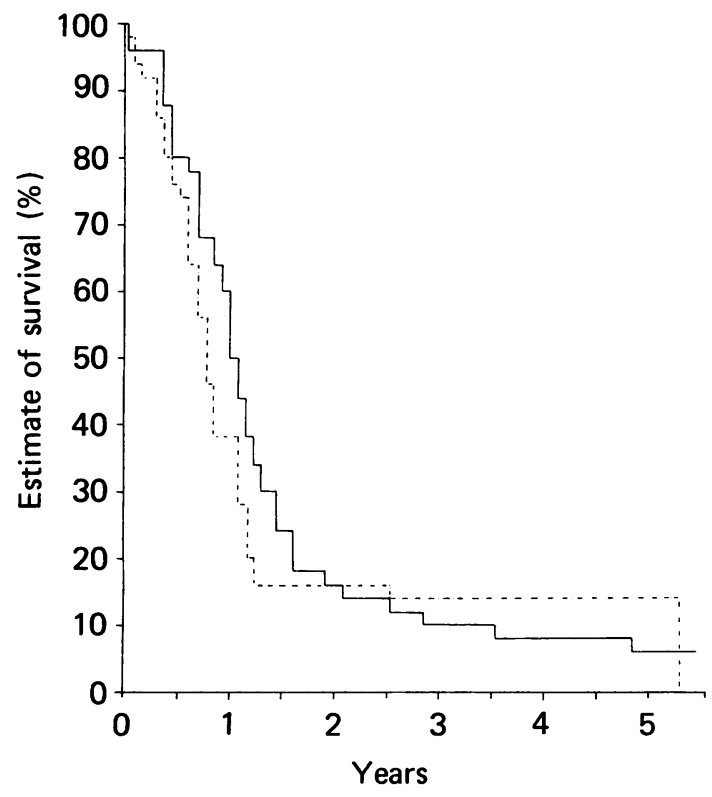

Fig 2 Life table for 33 operable, operated, patients (-.-.-) and for 46 operable but non-operated, patients (-).

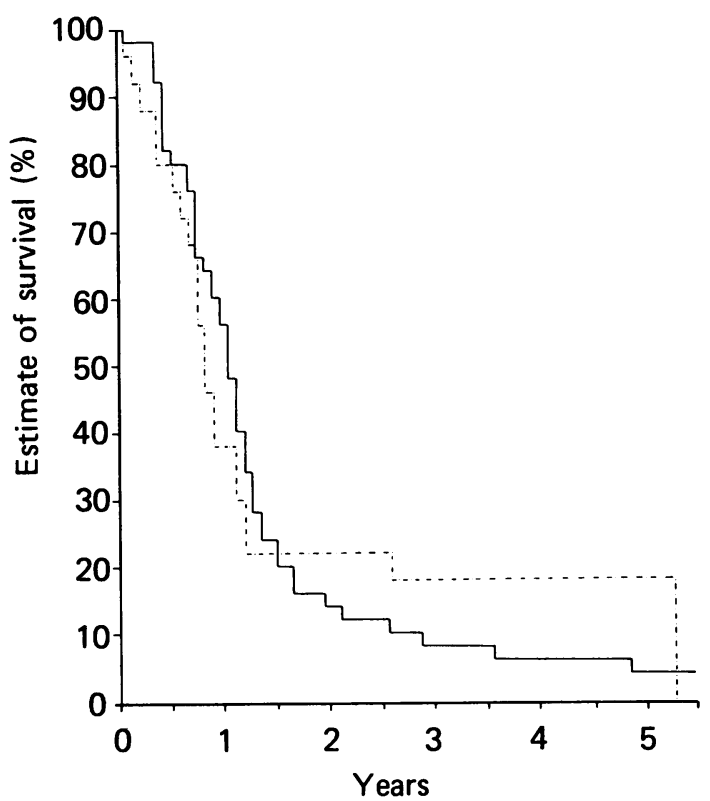

Fig 3 Life table for 24 patients who had resections (-.-.-) and for 55 patients who did not have resections (-).

tive reviews of data on treatment often covering 10-15 years. Experience from such series ${ }^{4}{ }^{12}$ suffers from the uncontrolled selection of patients undergoing surgery and from the bias of retrospective formulation of questions. The current series is also retrospective but benefits from the fact that our departments act as referral centres for almost all patients with small cell carcinoma from a region of about 2 million inhabitants. Patients with poor performance status were not exluded from the treatment trials, thus permitting a reliable estimate of operability in small cell carcinoma.

The effect of surgery in small cell carcinoma can be evaluated only by comparison of operated and non-operated patients, preferably in a prospective trial. The comparability of such patients have to be based on preoperative criteria. General examination, chest radiography, and bronchoscopy or mediastinoscopy, used in this retrospecitve study, could equally have been applied in a prospective trial. Patients without a preoperative diagnosis of small cell carcinoma must be excluded from the comparison, not being available for prospective study and being without counterparts among nonoperated patients.

In a prospective trial one would demand a well balanced allocation of operated and non-operated patients to various chemotherapy regimens. This series was retrospectively recruited from three gen- 
erations of controlled trials of chemotherapy and irradiation, in which the following median durations of survival were observed in patients with limited disease: 40 and 44 weeks, ${ }^{17} 48$ and 52 weeks, ${ }^{18}$ and 48 and 50 weeks. ${ }^{21}$ The imbalances with regard to chemotherapy between the operated and nonoperated patients in this comparison thus have had no major impact on the overall survival observed in each of the groups. On the basis of these conditions the present analysis indicates that a treatment policy of surgery before chemotherapy with or without radiotherapy does not lead to an overall prolongation of survival or to a greater survival rate.

We cannot exclude the possibility that complete resection may improve the chances of cure in a small proportion of patients, but in the present study of operable patients the prognosis of 11 patients with complete resections plus 13 with incomplete resections was not superior to that of the non-resected patients, indicating that surgical tumour reduction before chemotherapy does not per se result in superior results of treatment. Improved control of a resected primary tumour might be anticipated, but could not be proved. The divergence of clinical and necrospy findings indicates that clinical relapse patterns in resected patients must be interpreted with caution. Disappointing preliminary results of adjuvant surgery in those with primary unresectable tumours $^{1314}$ further supports the observation that only a highly selected group of "resectable" patients may benefit from resection. A definitive answer about the role of surgery in this disease requires careful study and much more accurate preoperative identification of the highly selected subset of patients for whom surgical resection is presumed to be beneficial.

We thank our colleagues in the departments of thoracic surgery at the Rigshospitalet, Bispebjerg Hospital, and Gentofte County Hospital, to whom we are grateful for excellent cooperation throughout the years.

\section{References}

1 American Joint Committee for Cancer Staging and End-Results Reporting. Staging of lung cancer. Chicago: Task Force On Lung Cancer, 1979.

2 Mountain CF, Carr DT, Anderson WAD. A system for the clinical staging of lung cancer. Am J Roentgenol 1974;120:130-9.

3 Watson WL, Berg JW. Oat cell lung cancer. Cancer 1962;15:759-68.

4 Shore DF, Paneth M. Survival after resection of small cell carcinoma of the bronchus. Thorax 1980; 35:819-22.

5 Martini N, Wittes RE, Hilaris BS, Hajdu SJ, Beattie EJ, Golbey RB. Oat cell carcinoma of the lung. Clin Bull 1975;5:144-8.

6 Taylor AB, Shinton NK, Waterhouse JAH. Histology of bronchial carcinoma in relation to prognosis. Thorax 1963; 18:178-81.

7 Goldman KP. Histology of lung cancer in relation to prognosis. Thorax 1965;20:298-303.

8 Lennox SC, Flavell G, Pollock DJ, Thompson VC, Wilkins JL. Results of resection for oat-cell carcinoma of the lung. Lancet 1968;ii:925-7.

9 Hansen HH. Management of small cell anaplastic carcinoma, 1980-1982. In: Ishikawa S, Hayata Y, Suemasu $\mathrm{K}$, eds. Lung cancer. Amsterdam: Excerpta Medica, 1982:31-77.

10 Karrer K, Denck H, Pridun N, Zwintz E. Combination of early surgery for cure and polychemotherapy in small-cell bronchial carcinoma. In: Spitzy $\mathrm{KH}$, eds. Proceedings of 13th International Congress of Chemotherapy. Vienna: Verlag H Egermann, 1983.

11 Shields TW, Higgins GA, Matthews MJ, Keehn RJ. Surgical resection in the management of small cell carcinoma of the lung. J Thorac Cardiovasc Surg 1982;84:481-8.

12 Meyer JA, Comis RL, Ginsberg SJ, et al. Phase II trial of extended indications for resection in small cell carcinoma of the lung. $J$ Thorac Cardiovasc Surg 1982;83:12-9.

13 Valdivieso M, McMurtrey MJ, Farha P, Frazier $\mathrm{OH}$, Spitzer G, Mountain CF. Prospective evaluation of adjuvant surgical resection in small cell lung cancer. Proc Am Soc Clin Oncol 1984;3:220.

14 Comis R, Meyer J, Ginsberg S, Poiesz B, DiFino S, Gullo J. The impact of TNM stage on results with chemotherapy and adjuvant surgery in small cell lung cancer. Proc Am Soc Clin Oncol 1984;3:226.

15 World Health Organisation. International histological classification of tumors: histological typing of lung tumors. 2nd ed. Geneva: WHO, 1981.

16 Hansen HH, Dombernowsky P, Hansen M, Hirsch F. Chemotherapy of advanced small cell anaplastic carcinoma. Superiority of a four-drug combination to a three-drug combination. Ann Intern Med 1978; 89: $177-81$.

17 Hansen HH, Dombernowsky P, Hirsch FR, Hansen M, Rygård J. Prophylactic irradiation in bronchogenic small cell anaplastic carcinoma. A comparative trial of localized versus extensive radiotherapy. Including prophylactic brain irradiation in patients receiving combination chemotherapy. Cancer 1980;46:279-84.

18 Dombernowsky $\mathrm{P}$, Hansen $\mathrm{HH}$, Hansen $\mathrm{M}$, et al. Treatment of small cell anaplastic bronchogenic carcinoma. Results from two randomized trials. In: Hansen HH, Dombernowsky $\mathrm{P}$, eds. Second World Conference on Lung Cancer, Copenhagen, June 9-13 1980. Amsterdam: Exerpta Medica, 1980:149 (abstract).

19 Østerlind K, Sørenson S, Hansen HH, et al. Treatment of advanced small cell carcinoma of the lung: continuous versus alternating combination chemotherapy. Cancer Res 1983;43:6085-9.

20 Østerlind K, Hansen HH, Dombernowsky P, Rørth FM, Sørenson S, Vindeløv L. Combination chemotherapy of small cell lung cancer based on in vivo cell cycle analysis. Results of a randomized trial of 
254 pts. Proc Am Assoc Cancer Res 1982;23:154 (abstract).

21 Hansen M, Østerlind K, Dombernowsky P, Sørenson $S$, Hansen HH. Cyclic alternating chemotherapy in small cell bronchogenic carcinoma. Results of a randomized trial of 222 pts. Proc Am Soc Clin Oncol 1983;2:201 (abstract).

22 Armitage P. Statistical methods in medical research. Oxford: Blackwell Scientific Publications, 1971.

23 Peto R, Pike MC, Armitage P, et al. Design and analysis of randomized clinical trials requiring prolonged observation of each patient II. Br J Cancer 1977;35:1-39.

24 Anonymous. Small-cell carcinoma of the bronchusreal progress is hard to come by. Lancet 1980;i:77-8.

25 Hansen HH, Hansen M, Rørth M, Dombernowsky P. Small-cell carcinoma of the bronchus. Lancet 1980;i:416 (letter).

26 Oldham RK, Greco FA. Small-cell carcinoma of the bronchus. Lancet 1980; i:478 (letter).

\section{Book notices}

Toxic oil syndrome: mass food poisoning in Spain. $\mathrm{P}$ Grandjean and S Tarkowski. (Pp 92; Sw fr 16.) World Health Organisation, Copenhagen. 1984.

Severe lung damage was the most prominent feature of the acute stage of the epidemic described in this book, which reached its peak in its sixth week, when about 1800 new cases were reported. The notification rate fell steeply to below 100 cases per week 10 weeks later and, although many individuals entered a chronic vasculitic stage of the disease (in which lung disease was again notable) and occasional new cases were still being notified a year later, the whole episode was swift and brief, so that few studies could be undertaken at the time. This report published by the World Health Organisation results from a meeting of experts convened two years later to consider all aspects of the disaster. It gives a clear account of the clinical manifestations, investigations, treatment, and pathological findings in affected individuals and it also presents a summary of the epidemiological, biochemical, and toxicological information which became available as the cause became clear. There are, under each heading, a remarkable number of uncertainties. For example, it is still not clear what the toxins were or how they were produced. Work is, of course, continuing on some of the problems and important lessons may yet be learned; but this small book is likely to remain a useful tool whenever this or similar poisonings are discussed because of its convenient presentation of a large amount of detailed observation made at the time.
Allergy: immunological and clinical aspects. MH Lessof. (Pp 474; £29.50.) John Wiley and Sons. 1984.

This book gives a standard account of practice relating to allergy by predominantly British authors. Considerable emphasis is put on the mechanisms of disease, including the immunology and pharmacology of mediators. There are specific sections on diagnostic methods such as skin tests, bronchial provocation testing, and laboratory investigation of allergic diseases. There then follows a series of chapters relating to each specialty. The largest chapter is on respiratory allergy. Also of interest to respiratory physicians is a comprehensive chapter on allergy in infancy and childhood, a clear account of the problems of food intolerance and allergy, a chapter on drug allergies (including pulmonary reactions), and a clear presentation of the role of immunotherapy (desensitising injections) that is in no way overstated. There are also chapters on allergy of the skin, eye, ear, kidney, and joints. The book is of more value for general reading than for reference. I missed a clear account of the taking of an allergic history, particularly relating to inhalant allergy. Moreover, there is no serious discussion of less conventional forms of allergy practice. The allergens discussed are also largely relevant to practice relating to allergy in the United Kingdom.-P S B 